\title{
Experiential Learning in MPA Programs: A Case for Complementarity between Internship and Service Learning Requirements
}

John David Gerlach, Western Carolina University

Tyler P. Reinagel, Independent Scholar

ABSTRACT Experiential learning is a growing practice in higher education today. Master of Public Administration (MPA) programs use experiential learning to expose students to application and reinforcement of academic theories and concepts. This most often is accomplished through a required internship. This article argues for the addition of service learning requirements to MPA curricula. A complementary relationship between internship and service learning requirements yields four primary benefits: (1) further involvement of pre-service and in-service students in experiential-learning activities; (2) additional exposure to real-life application of course concepts; (3) better and more targeted classroom reinforcement mechanisms; and (4) additional community benefit. Complementarity between internship and service learning requirements allows the best of each experiential-learning approach to augment the other. We contend that this produces better-prepared MPA graduates by exposing them to a more diverse set of immersive learning opportunities and application scenarios.

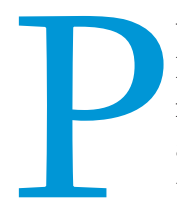

ublic administration is a field characterized by doing Pressman and Wildavsky (1973) defined implementation in a manner that firmly places the field of public administration in a category of action. Administration has been perceived as a science since the work of Woodrow Wilson (1887), and we know science as a process of trial and error. It is through experimentation that we learn in any scientific pursuit. In this spirit, experiential learning has pervaded public-administration education in recent years. The belief is now widespread that public-administration training should extend beyond the classroom to the outside world such that students may immerse themselves in administration and policy implementation (Bushouse and Morrison 2001; Imperial, Perry, and Katula 2007; Whitaker 2004). What remain

John David Gerlach is Master of Public Affairs director and assistant professor of political science and public affairs at Western Carolina University. He can be reached at jdgerlach@email.wcu.edu.

Tyler P. Reinagel can be reached at tyler.reinagel@gmail.com. unclear are the most appropriate methods for achieving this in Master of Public Administration (MPA) curricula.

This article makes a case for the coexistence of two widely accepted forms of experiential learning-internship and service learning requirements-in MPA programs. We are not suggesting that one form is superior to the other but rather that the two should coexist in a mutually reinforcing construct. We highlight the benefits of using both in well-rounded MPA curricula. The basis for the proposed relationship between internship and service learning experiences is Svara's (2001) notion of complementarity. Although initially presented as a framework for the relationship between administrators and elected officials, his complementarity relationship "entails separate parts, but parts that come together in a mutually supportive way. One fills out the other to create a whole" (Svara 2001, 179). Complementarity between internship and service learning requirements in MPA programs works in a similar way. The benefits of each have tremendous potential to work in concert to provide a level of experiential learning that upholds the spirit of public-administration education by immersing students in the doing that characterizes the field. 


\section{EXPERIENTIAL LEARNING}

Many contemporary scholars have made a strong case for experiential learning as a means by which to supplement traditional classroom experiences (Brown and Behrman 2008; Kolb 1984; Mitchell and Poutiatine 2001; Schettler 2002). Brown and Behrman (2008, 585) asserted, “Today's student body is older than in the past, with many students already having had substantial 'real-world' experience; thus, this approach [i.e., traditional classroom lecture] may no longer be so suitable." An argument may be made that pre-service students who lack hands-on experience are those most in need of experiential-learning opportunities. Regardless, experiential learning has become a popular approach to public-administration education (Bushouse and Morrison 2001; Imperial, Perry, and Katula 2007; Whitaker 2004).

Bushouse and Morrison (2001) proposed that service learning can enrich the practicum (or capstone) experience for MPA students in applicable programs. The practicum alone is not synonymous with service learning in this model but rather augments a student's capstone experience. This is not unique to public affairs and administration programs. The positive influence of service learning has been seen in graduate business (Andrews 2007; Wittmer 2004), nursing (Cohen and Milone-Nuzzo 2001), engineering (Mostafavi et al. 2013), and information-systems programs (Hoxmeier and Lenk 2003). Community-oriented service learning serves to further develop the practical skills developed in these specialized fields of study. This approach does not eliminate traditional classroom education but instead supplements it, in what Mitchell and Poutiatine (2001, 180; cited in Brown and Behrman 2008) called a "process of doing, observing, thinking, and reflecting."

Two experiential-learning techniques recently have become prominent in public-administration education: internship and service learning requirements. A 2010 survey of MPA programs conducted by the national accrediting body-the Network of
Schools of Public Policy, Affairs, and Administration (NASPAA) revealed that $93 \%$ of MPA programs offer an internship program to their students, although not all require it (NASPAA 2010). However, NASPAA (2003) is rather hands-off with regard to oversight of internships in accredited MPA programs, providing yet another reason to further study the benefits. Service learning represents a relatively new addition to public-administration experiential learning, which NASPAA standards have not yet addressed.

Imperial, Perry, and Katula (2007) pointed to 1990 as the beginning of a groundswell of citizen-service literature. This date coincides with the widespread incorporation of service learning opportunities in MPA programs across the country. Our in-depth discussion of internships and service learning opportunities in NASPAA-accredited MPA programs begins by examining the similarities and differences in the two methods of experiential learning. Table 1 is a comparison of the internship and the service learning approaches, illustrating that the former may be viewed as more student-oriented whereas service learning projects have a unique community benefit. We continue by exploring these similarities and differences in greater depth before suggesting a complementary relationship in MPA curricula.

\section{Internships in MPA Programs}

NASPAA does not mandate that accredited MPA programs require an internship or even that they offer an optional internship component (NASPAA 1977; 2003). NASPAA (1977) stated, "Although we think that the internship can be a valuable part of a public-administration program, we take no position that it must be part of all programs." NASPAA (2003) further stressed the optional nature of internships, providing guidance to MPA programs to "adapt and flesh out the NASPAA Internship Guidelines so that they can be used by program directors and faculty to encourage" internships in which "content, duration, and other factors may vary." Regardless of the lack of a NASPAA mandate,

Table

Internships versus Service Learning in MPA Programs

Internship

\begin{tabular}{ll} 
Motive & $\begin{array}{l}\text { Apply classroom knowledge/skillsets in practical } \\
\text { environment/workplace experience }\end{array}$ \\
\hline Primary Target Beneficiary & Student \\
\hline Initiative & $\begin{array}{l}\text { Student initiating contact with host agency for } \\
\text { individual and customized plan of work }\end{array}$ \\
\hline Engagement & $\begin{array}{l}\text { Work schedule coordinated between student } \\
\text { and host agency with minimal faculty involvement }\end{array}$ \\
\hline Credit & $\begin{array}{l}\text { May or may not be included in academic curriculum; } \\
\text { may or may not receive academic credit }\end{array}$ \\
\hline Obstacles & $\begin{array}{l}\text { Ensuring consistency across student experiences, } \\
\text { regardless of host agency }\end{array}$
\end{tabular}

Outputs

Intern self-evaluations; host-agency evaluation
On-the-job experience/training for students

Service Learning

Apply classroom knowledge/skillsets in community or civic function for public benefit from applied learning Community

Faculty initiating contact with public or community agency for concerted effort

Service responsibilities coordinated among class, faculty, and community agency/organization

Core component of credit-earning academic course

Instilling a long-term sense of obligation to public service among student participants

Ensuring sustainable and ongoing benefit for community

Student assessments of their work groups (individual efforts) and sponsor organizations (management and performance); sponsor-organization assessments of student work-group performance

Results

Instilled sense of civic responsibility in students and sustainable relationship between community organization and faculty/program/institution 
the organization provides guidelines on structuring internship programs and sees particular value in them as part of publicadministration education. Other scholars do as well. Henry (1979) argued that internships strengthen relationships, particularly between universities and governments. Wheeland and Palus (2010) discovered through an exit survey that $72 \%$ of MPA graduates believed their internships to be "very valuable" experiences. Ashmore, Lynch, and Treldkeld (1981) also addressed the benefits of internship programs when they proposed five key functional areas of value as an experiential-learning tool: (1) building strength of program curricula, (2) enhancing strength and stability of recruitment, (3) providing consistency in graduate placement, (4) developing professionalism and workplace skillsets among students, and (5) maintaining the relevance of internship programs.

Internships within NASPAA-accredited MPA programs follow one of five curriculum models (Reinagel and Gerlach 2015), as follows:

1. Internship is required for credit in lieu of face-to-face courses toward degree requirements.

2. Internship is required for credit in addition to face-to-face courses toward degree requirements.

3. Internship is required for credit with an alternative option for in-service students. ${ }^{1}$

4. Internship is required but not for academic credit.

5. Internship is not required.

Of the 165 NASPAA-accredited MPA programs, 115 use one of the first three models, requiring an internship for academic credit (Reinagel and Gerlach 2015). Additionally, 39 NASPAA-accredited programs that do not require internships offer the experience and academic credit for students who opt to participate (Reinagel and Gerlach 2015). This evidence suggests that internships are widely regarded in public-administration education as worthwhile and effective means of experiential learning. However, their use raises an important question related to the composition of MPA cohorts. Are internships adequately addressing the learning needs of both pre-service and in-service MPA students? degree to advance their career. They have experience in the field and an internship may well serve little purpose for them. Several MPA programs require internships but permit in-service students to opt for an alternative practicum-type assignment to fulfill that requirement and earn academic credits (i.e., Reinagel and Gerlach's third model) (Reinagel and Gerlach 2015). However, internships can have value to in-service students. They provide opportunities to broaden professional horizons, to network, and to witness the direct application of classroom concepts to unique and challenging scenarios they otherwise may not encounter in their own jobs.

\section{Service Learning in MPA Programs}

Bringle and Hatcher (1996) believed that service learning is likely to increase the understanding of course material. This typically is accomplished by immersion in service activities that require students to apply course materials to real workplace situations. Although the trend may be a more recent phenomenon than the internship approach to experiential learning, it is becoming increasingly commonplace across several disciplines. In the field of health care, service learning is used to train students to become "change agents" in their community by developing a keen social responsiveness to augment their classroom training (McMenamin, McGrath, Cantillon, and MacFarlane 2014). Nursing students are taught health policy by immersion in community-health populations through service learning (O'Brien-Larivee 2011). Service learning also is used in social-work and criminal-justice programs. Madden, Davis, and Cronley (2014) compared the use of service learning in the two disciplines, finding that whereas social-work programs employ the approach more frequently than criminal-justice programs, both use service learning with few implementation differences. More broadly, service learning has been shown to break down cultural stereotypes (Knecht and Martinez 2012). These service learning experiences are designed to supplement classroom teaching and reinforce traditional teaching methods while also providing a community service to public and nonprofit organizations.

The benefits of service learning are many, including another mechanism by which students learn. In addition to reaching

\section{This evidence suggests that internships are widely regarded in public-administration education as worthwhile and effective means of experiential learning.}

Although the overall value is widely accepted, achieving a successful balance between pre-service and in-service students in structuring and implementing internships is an ongoing process (Reinagel and Gerlach 2015).

Seeking higher value for internships among both pre-service and in-service students entails examining how every type of student may learn or at least how they may be used to learning. Pre-service students typically enter graduate school immediately following their undergraduate work. They may be adept at learning in the classroom setting but also may be hindered by their strict academic approaches to learning. Wolf (1979) asserted that pre-service students may think and learn in "silos" rather than with a mind toward real problems and organizational challenges. In-service MPA students often want to complete the auditory and visual learners in the classroom, service learning involves the application of concepts. Schettler (2002) called this "learning by doing." Most know this type of learning as "kinesthetic," or learning by touch. Service learning projects often are assigned within a particular course and require the participation of faculty, students, and outside organizations. Faculty benefits include allowing students other mechanisms of learning so that course concepts are witnessed outside the classroom silo. Faculty also may serve as mentors and advisors while overseeing students' service learning projects. Service learning can be an opportunity to engage the community and build ties with key agencies and organizations that graduate programs such as those in public administration often seek. Public and nonprofit agencies and organizations benefit from the free 
labor (i.e., graduate labor, in the case of MPA service learning), the ability to identify potential job candidates, and the relationships formed with local academic institutions.

Littlepage, Gazley, and Bennett (2012) conducted an empirical analysis of the capacity of nonprofit organizations to use service learning students. They found that whereas agency size and capacity are indicative of the capabilities to take on service learning students, willingness to participate also is tied to past experiences and perceptions of student benefits. Nonprofit organizations overwhelmingly endorsed the community benefits of service learning (Littlepage, Gazley, and Bennett 2012).

Service learning has become increasingly common in MPA programs (Whitaker 2004). In fact, it has become so prevalent that efforts to identify best practices have been promulgated. Most notably, Imperial, Perry, and Katula (2007) offered seven design principles for incorporating service learning into public-affairs programs, including (1) explicit connections between the service activity and the learning objectives, (2) reflection, (3) appropriate time commitment, (4) student input, (5) faculty commitment, (6) perceptible impacts, and (7) feedback loops. However, the popularity of service learning in public-administration education has the potential to conflict with internship requirements. Although the two experiential-learning techniques share some benefits (i.e., student immersion in workplace realities, community service, and reinforcement of classroom concepts), they also have differences (see table 1). Thus, a means by which to allow service learning and internships to successfully coexist can make public-administration education all the more impactful and desirable.

\section{Integration of Service Learning into MPA Curricula}

Whereas an internship has a long-standing role in MPA programs (and higher education in general), its function is different than that of engaged service learning. Whereas an internship is largely focused on student training and workplace exposure, service learning serves as a mutually reinforcing relationship and the student population is naturally transient. The relationship tends to be short term but it establishes a student's sense of public-service obligation, and evidence indicates a greater "understanding of social issues" afflicting multiple communities (Eyler, Giles, and Braxton 1997). For the community, the influx of new students brings consistently fresh perspectives to community needs and challenges. An example of the student-community dynamic is useful in understanding this phenomenon.

A recent application of service learning in a NASPAA-accredited MPA program occurred in the public-administration subfield of nonprofit management. Students taking the MPA elective titled "The Nonprofit Sector," an overview course, were required to work in groups of three with a local nonprofit organization for a maximum of 20 hours outside of the classroom during the semester. Learning objectives included applying course concepts to a real-life setting, using managerial skills to solve a problem, and contributing to the community by strengthening a local nonprofit organization's internal capacity. One group worked with an animal-welfare nonprofit organization to develop a grant-seeking handbook that included a needs statement, grant opportunities, and a detailed organizational budget. The outcome of the service learning project was a product that aided the financial development of the nonprofit organization as well as positive student reflection on the learning objectives involved. One student in the group commented, "The service learning project was nice in that we helped an organization which really needed our help while practicing core nonprofit management principles learned in the classroom." Both student and community benefits were evident during this particular project as they helped one another achieve learning objectives and gain organizational capacity, respectively.

Communities also stand to benefit from the research expertise of the MPA faculty. Because research is used to inform teaching, faculty members possess the unique ability to provide MPA students and community partners cutting-edge information related to particular subfields of public administration. One challenge to

\section{Four core relationships stand to benefit from the service learning effort in MPA programs: (1) student-community, (2) faculty-community, (3) program-community, and (4) university- community. The community-oriented nature of these relationships is the primary distinction between service learning and the long-standing understanding of student internships.}

focused on the surrounding community. Often described as a "town-gown" relationship, it is complex, multifaceted, and everevolving (Bruning, McGrew, and Cooper 2006). However, it has grown from a largely logistical relationship based on municipal service delivery, public safety, and other public-sector functions into a mutually beneficial relationship in a broader notion of community development.

Four core relationships stand to benefit from the service learning effort in MPA programs: (1) student-community, (2) faculty-community, (3) program-community, and (4) universitycommunity. The community-oriented nature of these relationships is the primary distinction between service learning and the long-standing understanding of student internships.

The student-community dynamic is in the greatest state of flux because there is a natural "bookend" to time as a student, this dynamic is that faculty members must commit to the time to do this. Service learning, which requires a time commitment on behalf of students and their community partners, also requires the same of faculty members. Therefore, service learning can be applied in MPA programs only with sufficient participation from faculty. With other teaching, service, and research demands, faculty members may perceive oversight of service learning projects as an onerous task. However, when faculty commitment is present, students and community partners can benefit greatly from the research expertise of MPA faculty.

In addition to the individual student and faculty components, MPA programs in general provide benefits to their communities. Academic curricula address many components of the complex relationship between MPA programs and their communities (NASPAA 1977, 2003). Because service learning is currently a 
widespread experiential-learning technique, MPA programs provide an ideal launching pad for its benefits. By their nature, MPA programs are practitioner-oriented because they prepare students for public service in various subfields of public administration. NASPAA values the ability of MPA programs to reach surrounding communities through public service. Therefore, service learning can be unique in that it is already the charge of MPA programs to engage their surrounding communities through public service. Service learning is a natural avenue through which to accomplish this, and MPA programs can use service learning to achieve additional outreach-all while investing in experiential student learning and strengthening ties with local governments, nonprofit organizations, and other entities in the surrounding communities.

Last, and on the broadest level, structured service learning allows colleges and universities to enhance their engagement with communities and further drive their own core public-service and outreach obligations. The institution empowers programs, faculty, and students by providing "[c]onsistency across elements of mission definition, strategic priorities, budget actions, recognition and rewards, definitions of terms, internal and external communications, faculty development objectives, curricular philosophy, and community relationships" (Holland 1999). For communities, identification with a broader institution lends legitimacy and cohesiveness to a collection of potentially disjointed and fragmented relationships. Public universities in particular, and especially land-grant universities, are charged with positively engaging the surrounding regions. Service learning enhances their ability to accomplish this by providing yet another tie with the community resulting in various benefits. MPA programs can play a vital role in achieving this important university engagement.

\section{A CASE FOR COMPLEMENTARITY}

Internship and service learning opportunities, if not requirements, should coexist because there are benefits unique to each. in a nonprofit management course may require students to work in groups of three to five for a participating nonprofit organization, for a specific number of hours, on a specific issue, during a particular semester. Those groups likely will consist of a mixture of pre-service and in-service students-working, learning, and immersing themselves in application together. This provides for a different immersive learning experience and allows for classroom discussion based on not only similar but often shared experiences.

Experiential learning appears to be tailor-made for publicadministration education. The relationship between internships and service learning is an applied example of Svara's (2001) complementarity in which "...parts [that] come together in a mutually supportive way" (179). Therefore, the relationship between internships and service learning allows "one [to fill] out another to create a whole" (Svara 2001, 179). We believe this provides MPA programs four main benefits: (1) further involvement of pre-service and in-service students, (2) additional exposure to real-life application of course concepts, (3) better targeted classroom reinforcement mechanisms, and (4) additional community benefit.

The theory of complementarity most typically is applied to the relationship between elected officials and government administrators (Svara 1999). The theory relies on the existence of three factors: interdependency, reciprocal influence, and extensive interaction (i.e., between elected officials and administrators) (Svara 1999, 2006). We argue that these three factors are necessary for internships and service learning to provide the greatest benefit possible to students and communities associated with MPA programs. The differences illustrated in table 1 should not be viewed as reasons to use only one of the two experientiallearning methods. Rather, the interdependency of the two is important. Whereas internships provide individual students with greater immersion outside of the classroom setting, service learning requirements within MPA classes allow students

\section{Because internship and service learning are integrated into MPA curricula, it is incumbent on faculty to ensure that these experiential-learning techniques inform one another. This is a forced interaction by the faculty but necessary if the benefits of both approaches are to be fully realized.}

Internships typically offer more immersion in workplace scenarios by virtue of requiring more hours of the student. However, service learning projects provide more focus on one particular issue facing a government agency or nonprofit organization. Internships often are conducted solo, which provides additional one-on-one interaction between a student and a professional mentor. Conversely, service learning projects trend toward group work (Brown and Behrman 2008). Perhaps the most substantial difference between internships and service learning projects is the classroom component and the inherent divide between pre-service and in-service students. Without the common experience provided through service learning, an internship requirement lacks the opportunity for all students to learn from one another based on their experiences in similar experiential-learning scenarios. Service learning projects are typically requirements of particular courses rather than the program as a whole. For example, a service learning project to work with others to provide unique, focused benefits for community organizations. The two approaches can lead to reciprocal influence as well. Whether the internship experience precedes service learning or vice versa, lessons learned as a result of one can strengthen a student's experience in the other-even though one experience, by definition, must come first. For example, students who first participate in an internship can use their experiences working for a community organization in a service learning project. Also, their service learning experiences may prompt a more in-depth reflection about the internship experience, resulting in continued learning from the time-limited internship. Finally, the responsibility of the "extensive-interaction" component of complementarity advanced by Svara $(1999,2006)$ rests with the MPA program and its faculty. Because internship and service learning are integrated into MPA curricula, it is incumbent on faculty to ensure that these experiential-learning techniques inform one another. 
This is a forced interaction by the faculty but necessary if the benefits of both approaches are to be fully realized.

MPA programs face the double-edged sword of appealing to a wide range of students, particularly with regard to incorporating experiential learning into their curricula. Pre-service students often show great interest in internships as professional-development and experience- building tools (McCaffery 1979). In-service students may find these experiences redundant or may be excused from them by their program guidelines. Recent findings indicate that an increasing number of in-service students are interested in public administration. That segment of MPA students in the United States challenges traditional models and places changing demands on MPA curricula (Holmes 2012). This changing pre-service and in-service gap may benefit from the implementation of service learning in particular courses. Service learning projects allow pre-service and in-service students to work together in an experiential-learning environment. These projects provide class credit, community benefit, additional opportunities for networking, and the ability to apply course concepts in a focused manner. They often require a shorter time commitment of students, which is particularly appealing to in-service students. The greatest benefit in narrowing the pre-service and in-service gap may be the opportunity for students to learn from one another as they reflect on their common service learning experiences, participate in discussions with classmates and instructors, and ultimately make practical connections between core course material and application in their sponsor organization.

A second benefit of using both internships and service learning in MPA programs is that students are afforded additional opportunities to witness the application of public-administration concepts. management, budgeting, nonprofit management, health care administration, and so on. Service learning projects typically are assigned in subfield courses and allow faculty and students to tailor experiential learning to subfield-level concepts and theories. To a certain extent, internships also provide this; however, service learning opportunities often allow students to further engage and deepen their immersion in subfield-specific scenarios. A nonprofit-management student may develop a fundraising plan for a local nonprofit organization. A health-care administration student may work with a professional mentor to review how changes in health policy affect a local hospital. The nature of service learning adjusts the lens of experiential learning and complements the often broader work experience of an internship in a way that can be highly beneficial to an MPA student with more targeted and specific interests within public administration. This interdependency, reciprocal influence, and interaction comprise an application of Svara's $(1999,2001,2006)$ complementarity model, and it is a primary reason that internships and service learning requirements not only could but should exist in MPA programs.

A final advantage of complementarity among internship and service learning requirements is additional community benefit. As MPA programs (and universities) seek to further engage and serve their communities, additional experiential-learning avenues meet that objective. Internships offer community benefit in much the same way as service learning projects-they provide free or lowcost graduate assistance to public and nonprofit organizations in exchange for playing a substantial role in a student's experiential learning. Adding service learning to the traditional internship approach only increases these opportunities for MPA programs and their students to impact and interact with the community in

\section{Complementarity among internships and service learning requirements provides additional experiential-learning benefits to MPA programs, students, and surrounding communities by allowing each approach to supplement and build on the best the other has to offer.}

In a field of study characterized by action, implementation, and administration, students can benefit greatly from additional experiential learning. Whereas internships require a greater time commitment of students, service learning projects often are targeted and focused. In some ways, service learning projects can serve as "mini-internships" by allowing students to work for a sponsor organization alongside a professional mentor but focusing on a particular subset of public-administration concepts for a shorter period. This additional exposure to application scenarios provides students diversity in experiences of witnessing the inner workings of public and nonprofit organizations. Students also can broaden their professional networks and experience different work environments through internships and service learning, a benefit to both pre-service and in-service students.

Whereas most NASPAA-accredited MPA programs at least offer if not require an internship experience, service learning is a relatively recent approach to experiential learning in public administration. Programs that adapt service learning components to MPA courses achieve a greater level of complementarity and enhance their ability to offer targeted, focused reinforcement of classroom concepts and even internship experiences. Public administration is a field composed of several subfields: public a meaningful way. Experiential-learning requirements also provide additional opportunities for public and nonprofit organizations to play a role in training potential future employees.

Although internship requirements and opportunities may appear to address experiential learning on the proverbial MPA curriculum checklist, there is room for the service learning approach as well. Because some graduate programs may not be the appropriate setting for a complementary relationship between internships and service learning, public-administration education is a result of its highly applied nature. As we seek to train current and future administrators in the theories and management techniques of public administration, additional experiential learning further accomplishes the kinesthetic reinforcement of these academic concepts and can train more well-rounded administrators, managers, and analysts. Students develop a greater appreciation of the complexity of public management by sharing unique professional perspectives on common experiences.

\section{CONCLUSION}

The value of experiential learning in MPA programs is well documented (Bushouse and Morrison 2001; Imperial, Perry, and Katula 2007; NASPAA 1977, 2003, 2010; Whitaker 2004). We urge 
MPA faculty to consider supplementing traditional classroom lectures with not only strong internship programs but also service learning projects. This can be accomplished by identifying courses within the MPA program in which service learning is a natural fit. These typically are subfield-specific elective courses that allow students to further tailor their public-administration education to specific career goals. Complementarity among internships and service learning requirements provides additional experiential-learning benefits to MPA programs, students, and surrounding communities by allowing each approach to supplement and build on the best the other has to offer. The two approaches interact in a way that maximizes student learning and allows additional opportunities for MPA programs to build community relationships. This is the hallmark of complementarity, and learning by doing highlights the essence of public administration.

\section{ACKNOWLEDGMENTS}

The authors thank the anonymous peer reviewers of this article for their time and careful review of our work. Your recommendations are deeply appreciated. The authors also thank Alexandra O'Halloran, an MPA graduate (2015), for her insight into MPA service learning, its benefits, and student perception of the experiential learning method.

\section{NOTE}

1. In-service students are those who currently are working in the field of public administration as opposed to pre-service students who are not and may have no work-related experience before enrolling in the MPA program.

\section{REFERENCES}

Andrews, Christine P. 2007. "Service Learning: Applications and Research in Business." Journal of Education for Business 83 (1): 19-26.

Ashmore, Tim, Sherry Lynch, and Susan Treldkeld. 1981. "P.A. Programs in the Southeast: An Alumni and Student Perspective." Southern Review of Public Administration 6 (2): 211-29.

Bringle, Robert G., and Julie A. Hatcher. 1996. "Implementing Service Learning in Higher Education.” Journal of Higher Education 67 (2): 221-39.

Brown, Cheryl A., and Robert W. Behrman. 2008. "Capstone for Political Science Majors: The Content Is the Service." Journal of Public Affairs Education 13 (3/4): 585-91.

Bruning, Stephen D., Shea McGrew, and Mark Cooper. 2006. "Town-Gown Relationships: Exploring University-Community Engagement from the Perspective of Community Members." Public Relations Review 32 (2): 125-30.

Bushouse, Brenda, and Sara Morrison. 2001. "Applying Service Learning in Master of Public Affairs Programs." Journal of Public Affairs Education 7 (1): 9-17.

Cohen, Sally Solomon, and Paula Milone-Nuzzo. 2001. "Advancing Health Policy in Nursing Education through Service Learning." Advances in Nursing Science $23(3): 28-40$.

Eyler, Janet, Dwight E. Giles, Jr., and John Braxton. 1997. “The Impact of Service Learning on College Students.” Michigan Journal of Community Service Learning $4(1): 5^{-15}$

Henry, Nicholas. 1979. “Are Internships Worthwhile?" Public Administration Review 39 (3): $245-7$.

Holland, Barbara A. 1999. "Factors and Strategies that Influence Faculty Involvement in Public Service." Journal of Public Service and Outreach 4 (1): 37-44

Holmes, Maja Husar. 2012. "Raising the Ranks of Public-Sector Leaders: Results of a National Survey of Executive Masters of Public Administration Programs." Public Personnel Management 41 (3): 449-63.
Hoxmeier, John, and Margarita Maria Lenk. 2003. "Service Learning in Information Systems Courses: Community Projects That Make a Difference.” Journal of Information Systems Education 14 (1): 91-100.

Imperial, Mark T., James L. Perry, and Michael C. Katula. 2007. "Incorporating Service Learning into Public Affairs Programs: Lessons from Literature.” Journal of Public Affairs Education 13 (2): 243-64

Knecht, Thomas, and Lisa M. Martinez. 2012. "Engaging the Reluctant? Service Learning, Interpersonal Contact, and Attitudes Toward Homeless Individuals." PS: Political Science and Politics 45 (1): 106-11.

Kolb, David A. 1984. Experiential Learning: Experience as the Source of Learning and Development. Englewood Cliffs, NJ: Prentice-Hall.

Littlepage, Laura, Beth Gazley, and Teresa A. Bennett. 2012. "Service Learning from the Supply Side: Community Capacity to Engage Students." Nonprofit Management and Leadership 22 (3): 305-20.

Madden, Elissa E., Jaya Davis, and Courtney Cronley. 2014. "A Comparative Analysis of Service Learning in Social Work and Criminal Justice Education." Teaching in Higher Education 19 (5): 470-83.

McCaffery, Jerry L. 1979. "Perception of Satisfaction-Dissatisfaction in the Internship Experience." Public Administration Review 39 (May/June): 241-8.

McMenamin, Ruth, Margaret McGrath, Peter Cantillon, and Anne MacFarlane. 2014. "Training Socially Responsive Health Care Graduates: Is Service Learning an Effective Educational Approach?" Medical Teacher 36 (4): 291-307.

Mitchell, Matthew M., and Michael I. Poutiatine. 2001. "Finding an Experiential Approach in Graduate Leadership Curricula." Journal of Experiential Education $24(3): 179-85$

Mostafavi, Ali, James L. Huff, Dulcy M. Abraham, William C. Oakes, and Carla B. Zoltowski. 2013. "Integrating Service, Learning, and Professional Practice: Toward the Vision for Civil Engineering in 2025." Journal of Professional Issues in Engineering Education and Practice: B4013001.

Network of Schools of Public Policy, Affairs, and Administration (NASPAA). 1977. "Public Service Internship Guidelines." Available at www.naspaa.org/principals/ resources/internship.asp.

—. 2003. "Model Internship Guidelines." Available at www.naspaa.org/principals/ resources/modelintern.asp.

—. 2010. "Summary of NASPAA 2010 Internship Program Survey." Available at www.naspaa.org/execMPA/naspaa_surveys/SummaryNASPAA2010-InternshipProgramSurvey.pdf.

O’Brien-Larivee, Catherine. 2011. "A Service learning Experience to Teach Baccalaureate Nursing Students about Health Policy." Journal of Nursing Education 50 (6): 332-6.

Pressman, Jeffrey L., and Aaron B. Wildavsky. 1973. Implementation. Berkeley, CA: University of California Press.

Reinagel, Tyler P., and John D. Gerlach. 2015. "Internships as Academic Exercise: An Assessment of MPA Curriculum Models." Journal of Public Affairs Education 21 (1): 71-82.

Schettler, Joel. 2002. "Learning by Doing." Training 39 (4): 38.

Svara, James H. 2006. "The Search for Meaning in Political-Administrative Relations in Local Government." International Journal of Public Administration 29 (12): 1065-90.

. 2001. "The Myth of the Dichotomy: Complementarity of Politics and Admin istration in the Past and Future of Public Administration." Public Administration Review 61 (2): 176-83

_ 1999. "Complementarity of Politics and Administration as a Legitimate Alternative to the Dichotomy Model." Administration and Society 30 (6): 676-705.

Wheeland, Craig M., and Christine Kelleher Palus. 2010. "A Profile of Villanova University's Partnership with Local Government Managers." Journal of Public Affairs Education 16 (3): 487-509.

Whitaker, Gordon E. 2004. "Learning Through Action: How MPA Public Service Team Projects Help Students Learn Research and Management Skills." Journal of Public Affairs Education 10 (4): 279-94

Wilson, Woodrow. 1887. “The Study of Administration.” Political Science Quarterly 2 (2): 197-222.

Wittmer, Dennis P. 2004. "Business and Community: Integrating Service Learning in Graduate Business Education.” Journal of Business Ethics 51 (4): 359-71.

Wolf, James F. 1979. “The Student Responsibility Model of Public Service Internships." Southern Review of Public Administration 3 (2): 127-37. 